\title{
Radiographic analysis of the sacral-2-alar screw trajectory
}

\author{
Yulin Zhao ${ }^{1}$, Baisheng Yuan ${ }^{1 *}$, Yijun Han $^{2}$ and Binglei Zhang ${ }^{1}$
}

\begin{abstract}
Purpose: To explore the feasibility of sacral-2-alar (S2-alar) screw placement by measuring the length, diameter, and angle of the screw trajectory on computed tomography (CT).

Methods: This study selected 100 Han-nationality adults in northern China with a normal spine and pelvis. CT data were imported into PHILIPS software for reconstructing the 3D digital images. The optimal S2-alar screw trajectory was imitated on CT. Parameters including the length of the screw trajectory, sagittal angle, coronal angle, distance between the entry point and the spinous process, and minimum diameter of the screw trajectory were measured to evaluate the application of $\mathrm{S2}$-alar screws.
\end{abstract}

Results: In total, 48 males and 52 females were included. The average length of the left screw trajectory was $47.18 \pm 3.91 \mathrm{~mm}$. The sagittal angle was $29.06 \pm 4.00^{\circ}$. The coronal angle was $13.31 \pm 6.95^{\circ}$. The distance between the entry point and the spinous process was 21.0 (3.7) $\mathrm{mm}$. The minimum diameter of the screw trajectory was 17.1 (2.3) $\mathrm{mm}$. The average length of the right screw trajectory was $45.46 \pm 4.37 \mathrm{~mm}$. The sagittal angle was $23.33 \pm 4.26^{\circ}$. The coronal angle was $14.88 \pm 6.84^{\circ}$. The distance between the entry point and the spinous process was 22.8 (2.9) $\mathrm{mm}$. The minimum diameter of the screw trajectory was 16.9 (3.1) $\mathrm{mm}$. In women, the average length of the left screw trajectory was $44.80 \pm 3.66 \mathrm{~mm}$. The sagittal angle was $32.14 \pm 5.48^{\circ}$. The coronal angle was $16.04 \pm 7.74^{\circ}$. The distance between the entry point and the spinous process was $21.8(2.8) \mathrm{mm}$. The minimum diameter of the screw trajectory was 17.1 (5) $\mathrm{mm}$. The average length of the right screw trajectory was $44.01 \pm 3.72 \mathrm{~mm}$. The sagittal angle was $25.12 \pm 5.19$. The coronal angle was $16.67 \pm 8.34^{\circ}$. The distance between the entry point and the spinous process was $21.6(2.7) \mathrm{mm}$. The minimum diameter of the screw trajectory was $17(4.5) \mathrm{mm}$. As seen from the data, there were significant differences in the minimum diameter of the screw trajectory in both males and females. In females, there were also significant differences between the left and right sides in the coronal angle. Between males and females, there were statistically significant differences in the length of the screw trajectory. There were no statistically significant differences in the other parameters between males and females.

Conclusion: The optimal screw trajectory of the S2-alar screw can be found on CT. The length and deflection angle of the screw meet the clinical requirements. This method is easy to perform and feasible for clinical application.

Keywords: Second sacrum, Sacral ala, Screw, CT, Analysis

\footnotetext{
*Correspondence: yuanbaisheng3673@sina.com

${ }^{1}$ Department of Orthopedics, Qilu Hospital (Qingdao), Cheeloo College

of Medicine, Shandong University, No. 758 Hefei Road, Shandong 266035 Qingdao, China

Full list of author information is available at the end of the article
}

\section{Introduction}

Lumbosacral fusion procedures have been widely used in clinical practice. In the treatment of moderate-severe lumbar spondylolisthesis and degenerative scoliosis deformity, standalone sacral-1 (S1) screws have a higher rate of fixation failure. This is because (1) the stress of the distal screw is large; (2) the pedicle of the S1 vertebral original author(s) and the source, provide a link to the Creative Commons licence, and indicate if changes were made. The images or other third party material in this article are included in the article's Creative Commons licence, unless indicated otherwise in a credit line to the material. If material is not included in the article's Creative Commons licence and your intended use is not permitted by statutory regulation or exceeds the permitted use, you will need to obtain permission directly from the copyright holder. To view a copy of this licence, visit http://creativecommons.org/licenses/by/4.0/. The Creative Commons Public Domain Dedication waiver (http://creativeco mmons.org/publicdomain/zero/1.0/) applies to the data made available in this article, unless otherwise stated in a credit line to the data. 
arch is wide, while the screw is relatively short; and (3) the vertebra contains cancellous bone with less supporting strength. The clinical application of conventional sacral-2-alar (S2-alar) screws is limited due to their weaker pullout resistance. We found that the S2-alar screw trajectory became longer when the screw was placed on the sides of the sacral wings and had a larger angle in the sagittal plane. Therefore, we put forward the application of S2-alar screws. By increasing the screw angle and deflecting the head of the screw to the outside, the screw will cover a longer distance in the sacrum $[1$, 2]. Prolongation of the bony screw trajectory correspondingly increases the pullout resistance and, in turn, has the effect of enhanced distal fixation. Here, we measured the clinical data of Chinese S2-alar screws by computed tomographic $(\mathrm{CT})$ scans to provide the basis for clinical application.

\section{Materials and methods}

We randomly screened 100 Han-nationality adults in northern China. They included 48 men and 52 women. The mean age was $46.25 \pm 14.95$ years. The inclusion criteria were a basically normal spine and pelvis and no obvious scoliosis or kyphosis. The exclusion criteria were obvious radiographic scoliosis, kyphosis, transitional vertebra, or other malformations.

\section{Radiographic analysis}

The spine and pelvis were scanned by $\mathrm{CT}$, and threedimensional (3D) reconstruction was performed. The power was set at $120 \mathrm{kV}$ and $300 \mathrm{~mA}$. The rotation time was $750 \mathrm{~ms}$. The slice thickness was $1 \mathrm{~mm}$. CT data of lumbar-2 to the pelvis were imported into PHILIPS software (PHILIPS, EBW:V4.5.5.51035) for reconstructing the $3 \mathrm{D}$ digital images. The entry point was selected as the midpoint between the lateral border of the S1 and S2 foramens. Directing towards the sacral wing, the screw trajectory with the maximal screw distance in the sacrum was imitated as the optimal trajectory. Through repeated imitation by CT, it was concluded that the maximal bony screw trajectory could be reached with a proper angle in the sagittal and coronal planes. The distance between the entry point and the spinous process was measured to ensure normal installation of the connecting rod. The minimum diameter of the expected screw trajectory was measured to ensure normal installation of the screws.

The measurements were performed by two independent investigators. The data were collected and averaged.

\section{Imitation by CT and anatomical measurements of the screw trajectory}

The arrow in Fig. 1B indicates the entry point, and the arrow in Fig. $1 \mathrm{C}$ indicates the exit point.

\section{The length of the screw trajectory}

The transverse diameter and sagittal diameter of the trajectory can meet the requirements of the screw (Fig. 2). The entry point was selected as the midpoint between the lateral border of the S1 and S2 foramens. Directing towards the sacral wing, the screw trajectory with the maximal screw distance in the sacrum was imitated as the optimal trajectory. In this case, the trajectory length reached $45.34 \pm 3.96 \mathrm{~mm}$, which provided a sufficient holding force to improve the high complication rate in long-segment distal fixation (Fig. 3).

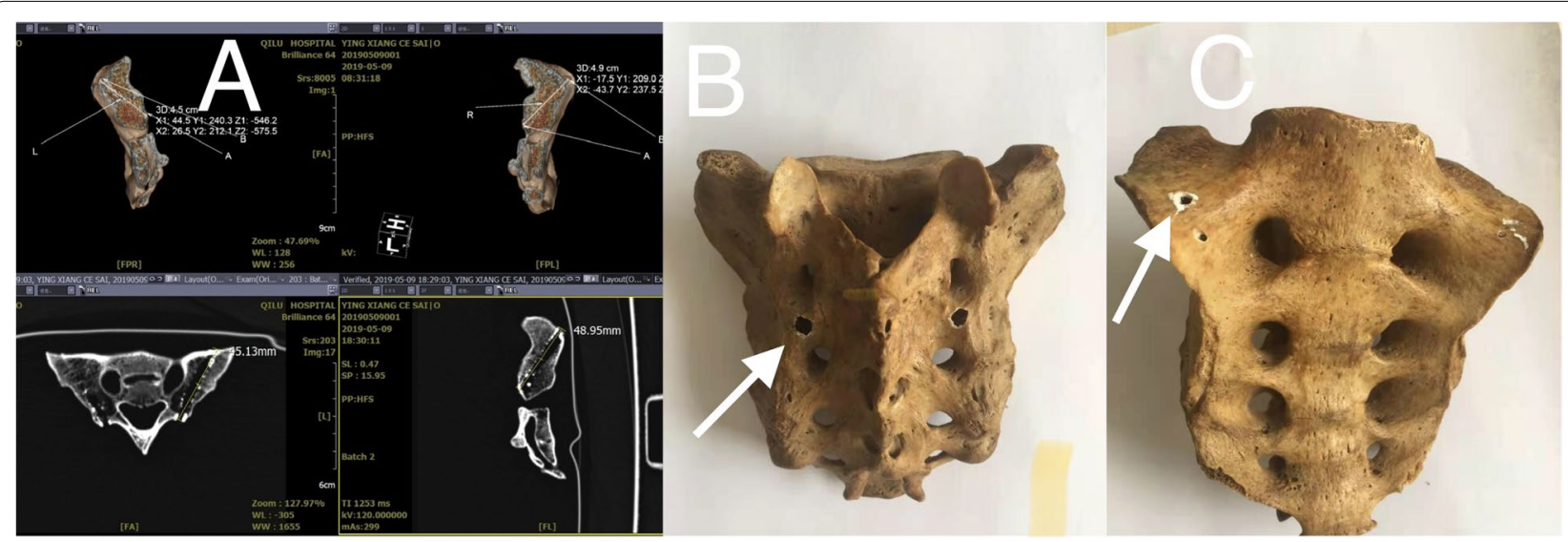

Fig. 1 Imitation by CT and anatomical measurements of the screw trajectory 


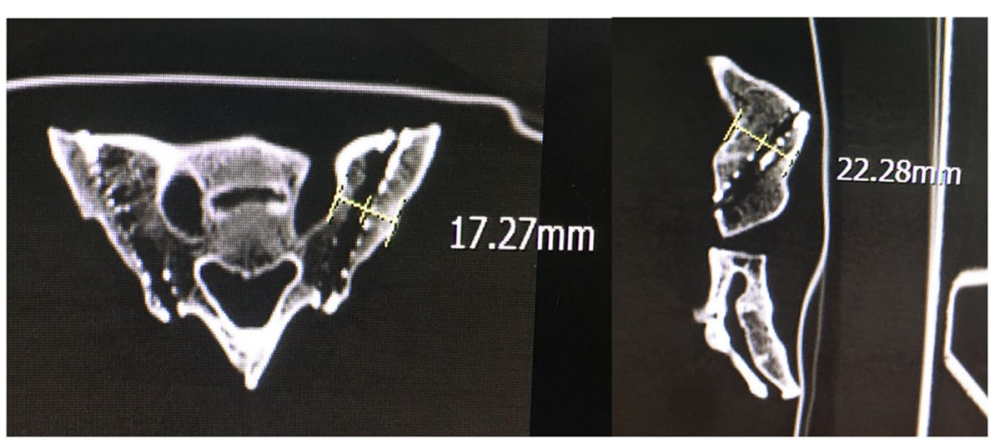

A

B

Fig. 2 A Transverse diameter and $\mathbf{B}$ sagittal diameter

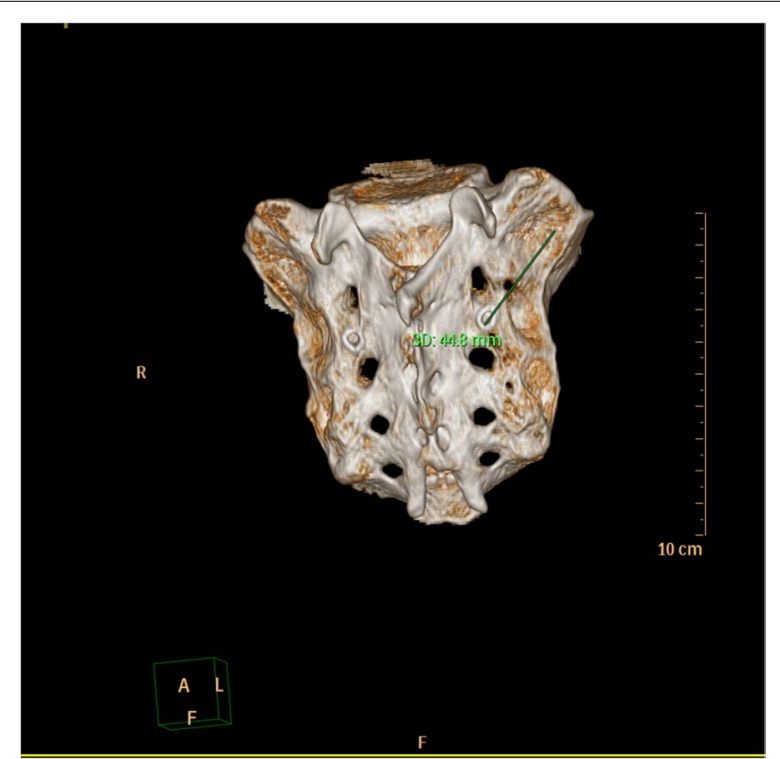

Fig. 3 Trajectory length

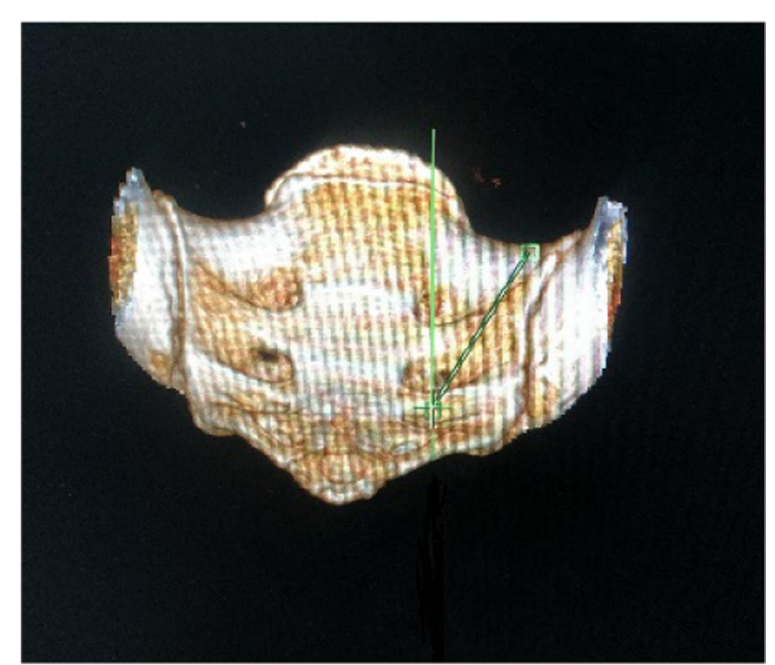

Fig. 4 Coronal angle

\section{Coronal angle}

The caudal trajectory angulation in the coronal plane was measured to meet the needs of screw placement in clinical practice (Fig. 4).

\section{Sagittal angle}

The caudal trajectory angulation in the sagittal plane was measured to meet the needs of screw placement in clinical practice (Fig. 5).

The distance between the entry point and the spinous process The vertical distance between the entry point and the middle line of the spinous process was measured to verify the accuracy of the entry point and to estimate the convenience of installation of the connecting rod (Fig. 6).

\section{Minimum diameter of the screw trajectory}

The minimum diameter of the imitated screw trajectory was measured to ensure safe placement of the screw with a diameter of 4.5-6.5 mm without cutting (Fig. 7).

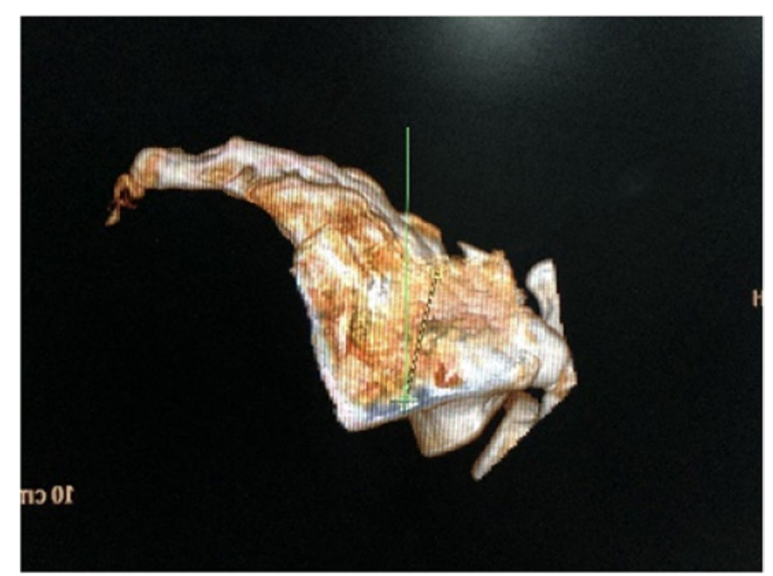

Fig. 5 Sagittal angle 


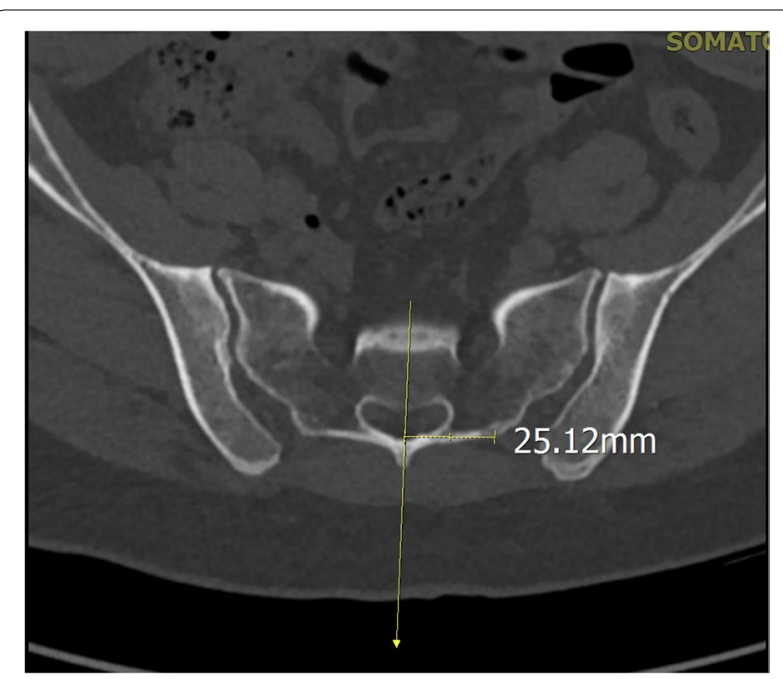

Fig. 6 The distance between the entry point and the spinous process

\section{Statistical analysis}

The Shapiro-Wilk method was used to test the normality of continuous variables. Variables that fit the normal distribution are described as the mean \pm standard deviation. Variables that do not fit the normal distribution are described as medians (interquaternary intervals). For the possible differences in parameters between sexes, an independent sample $t$ test was used for data conforming to a normal distribution, and the Mann-Whitney $U$ test was used for those not conforming to a normal distribution. For the comparison of left- and right-side parameters, the paired $t$ test was used for data in line with the normal distribution, while the Wilcoxon signed

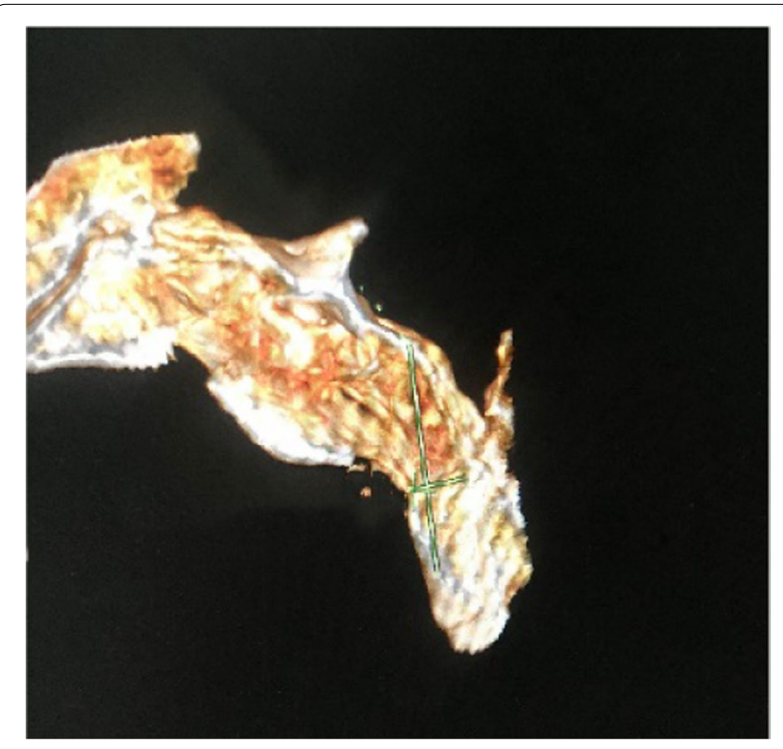

Fig. 7 The minimum diameter of the screw trajectory rank sum test was used for those not in line with the normal distribution. The statistical significance was set at $P<0.05$. All data were analyzed using SPSS.

\section{Results}

We measured the parameters of 100 normal subjects on CT to obtain S2-alar screw placement data. Forty-eight males and 52 females were included. In males, the average length of the left screw trajectory was $47.18 \pm 3.91 \mathrm{~mm}$. The sagittal angle was $29.06 \pm 4.00^{\circ}$. The coronal angle was $13.31 \pm 6.95^{\circ}$. The distance between the entry point and the spinous process was $21.0(3.7) \mathrm{mm}$. The minimum diameter of the screw trajectory was $17.1(2.3)$ $\mathrm{mm}$. The average length of the right screw trajectory was $45.46 \pm 4.37 \mathrm{~mm}$. The sagittal angle was $23.33 \pm 4.26^{\circ}$. The coronal angle was $14.88 \pm 6.84^{\circ}$. The distance between the entry point and the spinous process was 22.8 (2.9) $\mathrm{mm}$. The minimum diameter of the screw trajectory was $16.9(3.1) \mathrm{mm}$. In women, the average length of the left screw trajectory was $44.80 \pm 3.66 \mathrm{~mm}$. The sagittal angle was $32.14 \pm 5.48^{\circ}$. The coronal angle was $16.04 \pm 7.74^{\circ}$. The distance between the entry point and the spinous process was $21.8(2.8) \mathrm{mm}$. The minimum diameter of the screw trajectory was $17.1(5) \mathrm{mm}$. The average length of the right screw trajectory was $44.01 \pm 3.72 \mathrm{~mm}$. The sagittal angle was $25.12 \pm 5.19$. The coronal angle was $16.67 \pm 8.34^{\circ}$. The distance between the entry point and the spinous process was $21.6(2.7) \mathrm{mm}$. The minimum diameter of the screw trajectory was $17(4.5) \mathrm{mm}$ (Tables 1 and 2).

As seen from the data, there were significant differences in the minimum diameter of the screw trajectory between males and females. In females, there were also significant differences between the left and right sides in the coronal angle. Between males and females, there were statistically significant differences in the length of the screw trajectory. There were no statistically significant differences in the other parameters between males and females.

The results showed that the S2-alar screw had a sufficient screw trajectory length. The entry point of the screw had obvious anatomical marks, and the distance between the entry point and the spinous process was relatively fixed. The screw placement was operable and repeatable.

\section{Discussion}

Spinal malformation is common in clinical spinal surgery and is also one of the important reasons for surgical treatments of spinal diseases. Among these conditions, lumbar spondylolisthesis and degenerative scoliosis of the lumbar spine often require surgical correction and internal fixation. Severe cases often need fixation to the sacrum or 
Table 1 Comparison of individual parameters in males and females

\begin{tabular}{|c|c|c|c|c|c|c|}
\hline & \multicolumn{3}{|c|}{ Male $(n=48)$} & \multicolumn{3}{|c|}{ Female $(n=52)$} \\
\hline & Left & Right & $P$ & Left & Right & $P$ \\
\hline Length of the screw trajectory (mm) & $47.18 \pm 3.91$ & $45.46 \pm 4.37$ & $<0.01$ & $44.80 \pm 3.66$ & $44.01 \pm 3.72$ & 0.024 \\
\hline Sagittal angle $\left(^{\circ}\right)$ & $29.06 \pm 4.00$ & $23.33 \pm 4.26$ & $<0.01$ & $32.14 \pm 5.48$ & $25.12 \pm 5.19$ & $<0.01$ \\
\hline Coronal angle $\left(^{\circ}\right)$ & $13.31 \pm 6.95$ & $14.88 \pm 6.84$ & 0.014 & $16.04 \pm 7.74$ & $16.67 \pm 8.34$ & 0.337 \\
\hline $\begin{array}{l}\text { Distance between the entry point and the spinous } \\
\text { process }(\mathrm{mm})\end{array}$ & $21.0(3.7)^{\mathrm{a}}$ & $22.8(2.9)^{\mathrm{a}}$ & $0.001^{b}$ & $21.8(2.8)^{\mathrm{a}}$ & $21.6(2.7)^{\mathrm{a}}$ & $0.004^{b}$ \\
\hline Minimum diameter of the screw trajectory $(\mathrm{mm})$ & $17.1(2.3)^{\mathrm{a}}$ & $16.9(3.1)$ & $0.638^{\mathrm{b}}$ & $17.1(5)^{\mathrm{a}}$ & $17(4.5)^{\mathrm{a}}$ & $0.059^{b}$ \\
\hline
\end{tabular}

The Shapiro-Wilk test showed that the length of the nail track, the angle of the sagittal plane, and the angle of the coronal plane were all normally distributed $(P>0.05)$; the distance between the nail entry point and the spinous process and the minimum diameter of the nail path had a non-normal distribution

a the median (quartile spacing), ${ }^{b}$ the Wilcoxon sign rank sum test

Table 2 Comparison of parameters between males and females

\begin{tabular}{|c|c|c|c|}
\hline & Male $(n=48)$ & Female $(n=52)$ & $P$ \\
\hline Length of the screw trajectory (left) (mm) & $47.18 \pm 3.91$ & $44.80 \pm 3.66$ & 0.002 \\
\hline Length of the screw trajectory (right) (mm) & $45.46 \pm 4.37$ & $44.01 \pm 3.72$ & 0.075 \\
\hline Sagittal angle (left) $\left(^{\circ}\right)$ & $29.06 \pm 4.00$ & $32.14 \pm 5.48$ & 0.002 \\
\hline Sagittal angle (right) $\left(^{\circ}\right)$ & $23.33 \pm 4.26$ & $25.12 \pm 5.19$ & 0.065 \\
\hline Coronal angle (left) $\left({ }^{\circ}\right)$ & $13.31 \pm 6.95$ & $16.04 \pm 7.74$ & 0.068 \\
\hline Coronal angle (right) $\left(^{\circ}\right)$ & $14.88 \pm 6.84$ & $16.67 \pm 8.34$ & 0.244 \\
\hline Distance between the entry point and the spinous process (left) $(\mathrm{mm})$ & $21.0(3.7)^{\mathrm{a}}$ & $21.8(2.8)^{\mathrm{a}}$ & $0.423^{b}$ \\
\hline Distance between the entry point and the spinous process (right) (mm) & $22.8(2.9)^{\mathrm{a}}$ & $21.6(2.7)^{\mathrm{a}}$ & $0.143^{b}$ \\
\hline Minimum diameter of the screw trajectory (left) (mm) & $17.1(2.3)^{\mathrm{a}}$ & $17.1(5)^{\mathrm{a}}$ & $0.492^{b}$ \\
\hline Minimum diameter of the screw trajectory (right) $(\mathrm{mm})$ & $16.82 \pm 2.66$ & $16.54 \pm 3.55$ & 0.656 \\
\hline
\end{tabular}

The Shapiro-Wilk test showed that the length of the nail track, the angle of the sagittal plane, the angle of the coronal plane, and the right side of the minimum diameter of the nail track were normally distributed $(P>0.05)$; the distance between the nail entry point and the spinous process and the minimum diameter of the nail path had a non-normal distribution

${ }^{a}$ the median (interquartile interval), ${ }^{b}$ the Mann-Whitney $U$ test

even the pelvis to achieve the requirements of correction and stability. Complications such as loosening of internal fixation, broken screws, pseudarthrosis, and pain are often encountered after traditional spinal and pelvic fixation techniques [3, 4]. The use of iliac screws and trans-S2 sacroiliac screws has significantly reduced the complications associated with internal fixation. However, related clinical problems, such as sacroiliac joint degeneration and sacroiliac arthritis, have also been reported [5]. Neurovascular injury involving screw trajectory deviation of the iliac bone and sacroiliac joint is also one of the problems that needs to be given great attention [6].

Spinal pelvis fixation remains a challenging area in spine surgery for the treatment of moderate-tosevere spondylolisthesis and degenerative scoliosis and involves biomechanical balance problems, deterioration of physiological functions, and revision of internal fixation with a high failure rate. For severe degenerative scoliosis of the lumbar spine, severe spondylolisthesis, revision surgery, etc., long-segment fixation with distal fixation to the pelvis is often required. Distal fixation is of critical importance in thoracolumbar malformation surgery. Multiple studies [7] have shown that when S1 pedicle screws are used without auxiliary fixation, the incidence of pseudarthrosis is higher and this approach is associated with fixation failure and poor prognosis [8].

Due to the high failure rate of S1 screws, iliac screws and S2 ala-iliac (S2AI) screws were developed. The latter two have high reliability of internal fixation due to tricortical fixation. S2AI screws are especially popular because of their low notch and firm fixation. Both iliac screws and S2AI screws force the sacroiliac joint or directly fix the sacroiliac joint. Degeneration and fusion of the sacroiliac joint, as well as pain, are potential risks. S2-alar screws have been clinically applied since the 1980s and have received attention from and been researched by clinical peers. However, due to the short bony screw trajectory and insufficient holding force, the clinical application of traditional 
S2-alar screws must be abandoned. The development of sacral screws, from the initial Galveston iliac rod, Jackson sacral rod, and Kostuik trans-iliac rod to the later spine-iliac screw and trans-S2 sacroiliac screw [9-11], has resulted in a significant reduction in transstructural complications. The iliac screw, which connects the spine to the pelvis across the plane, greatly increases the stability of fixation [12]. Complications, including internal fixation fracture, delayed bone healing, pain, and skin ulceration, have also occurred with clinical use. In recent years, S2AI screws have been formed through exploration of the trajectory of trans-S2 sacroiliac screws. Numerous studies have demonstrated the effectiveness and stability of S2AI screws, as well as fewer pseudarthrosis formations and fewer internal fixation failures [13-17]. At the same time, some scholars have shown that screw fracture also occurs in the process of bone healing due to the micro-mobility of the sacroiliac joint [18]. In addition, the degeneration and pain of the sacroiliac joint might require further study. In terms of technical difficulty, S2AI requires more skilled screw placement techniques and better surgeons. This difficulty can be reduced through the application of intraoperative navigation technology but likely poses certain challenges to hospitals that lack this technology $[19,20]$. At present, S2AI has been established as the preferred fixation mode for the spine and pelvis. S2AI can provide relatively strong internal fixation and greatly reduce the problem of distal fixation failure. However, there are still new clinical problems in the clinical application of S2AI. Distal fixation across the joint to pelvic fixation may lead to new clinical problems. S2AI can reduce the incidence of complications mainly because of its stable distal fixation, which can achieve perfect distal fixation in the bone-healing stage [21].

In this paper, the radiographic measurements of S2-alar screws were described.

The entry point was selected as the midpoint between the lateral border of the S1 and S2 foramens. Directing towards the anterolateral of the sacral wing, because the anterolateral sacral wing has plenty of bone and ample space, the S2-alar screw did not pass through the sacroiliac joint. Its length and biomechanics might meet the requirements of screw placement. In this way, it could avoid stress or damage to the sacroiliac joint in the distal fixation at long segments and might effectively prevent or reduce later pain or degeneration of the sacroiliac joint and decrease postoperative complications. Our results showed that by adjusting the screw trajectory and deflecting the fixed S2 screw, the length of the screw trajectory reached $45.34 \pm 3.96 \mathrm{~mm}$ so that there was enough holding force to improve the drawbacks of traditional S2 screws. S2-alar screw placement is relatively simple, safe, and stable.

The sacrum is an irregular bone, and the S2-alar screw is a new screw placement method. 3D printing is also a method to improve the patient-doctor relationship and to avoid liabilities. Explaining the surgery to the patient using 3D models could improve his preoperative emotional status and could also help him overcome the fear of surgery.

Such models could also be used in defensive medical decision-making [22].

This study is only a preliminary work for the design and improvement of S2-alar screws. The results confirmed the feasibility of S2-alar screw placement. In the next step, we will conduct further finite element analysis and biomechanical experiments to confirm the reliability and stability of the improved S2-alar screw.

\section{Conclusions}

Through the above-described measurements, we found that there were few individual differences in the parameters of S2-alar screw placement. Although there were significant differences in the minimum diameter and length of the screw trajectory between males and females, all individuals could obtain the optimal screw trajectory. Based on the previous data, we proposed a scheme of S2-alar screw placement. By designing the screw trajectory and measuring the parameters, it was proven that the S2-alar screw could be applied to most people, which provides the radiographic basis for further verification of its clinical effectiveness.

\section{Abbreviations}

CT: Computed tomography; S2-alar: Sacral-2-alar; 3D: Three-dimensional; S2AI: S2 ala-iliac.

\section{Acknowledgements}

The authors thank all the staff of the Department of Orthopedics and Department of Radiology of Qilu Hospital (Qingdao), Cheeloo College of Medicine, Shandong University.

\section{Authors' contributions}

All authors contributed to the study conception and design. Material preparation, data collection, and analysis were performed by $Y Z, B Y$, and BZ. The first draft of the manuscript was written by $Y Z$, and all authors commented on previous versions of the manuscript. All authors read and approved the final manuscript.

\section{Funding}

The authors did not receive support from any organization for the submitted work.

Availability of data and materials

All data generated or analyzed during this study are included in this published article. 


\section{Declarations}

Ethics approval and consent to participate

All procedures followed were in accordance with the ethical standards of the responsible committee on human experimentation. This study was approved by the medical ethics committee of Qilu Hospital (Qingdao), Cheeloo College of Medicine, Shandong University. Informed consent was obtained from all patients included in the study.

\section{Consent for publication}

Not applicable.

\section{Competing interests}

The authors declare they have no competing interests.

\section{Author details}

'Department of Orthopedics, Qilu Hospital (Qingdao), Cheeloo College of Medicine, Shandong University, No. 758 Hefei Road, Shandong 266035 Qingdao, China. ${ }^{2}$ Department of Radiology, Qilu Hospital (Qingdao), Cheeloo College of Medicine, Shandong University, Qingdao, Shandong, China

Received: 4 June 2021 Accepted: 24 July 2021

Published online: 23 August 2021

\section{References}

1. Kwan MK, Jeffry A, Chan CYW, Saw LB. A radiological evaluation of the morphometry and safety of S1, S2 and S2-ilium screws in the Asian population using three dimensional computed tomography scan: an analysis of 180 pelvis. Surg Radiol Anat. 2012;34(3):217-27.

2. Park YS, Kim HS, Baek SW, Lee SH. Lumbosacral fixation using the diagonal S2 screw for long fusion in degenerative lumbar deformity: technical note involving 13 cases. Clin Orthop Surg. 2013;5(3):225-9.

3. Ilyas H, Place H, Puryear A. A comparison of early clinical and radiographic complications of iliac screw fixation versus S2 alar iliac (S2Al) fixation in the adult and pediatric populations. J Spinal Disord Tech. 2015:28(4):199-205

4. Tsuchiya K, Bridwell KH, Kuklo TR, Lenke LG, Baldus C. Minimum 5-year analysis of L5-S1 fusion using sacropelvic fixation (bilateral S1 and iliac screws) for spinal deformity. Spine (Phila Pa 1976). 2006;31(3):303-8.

5. Elder BD, Ishida W, Lo SL, Holmes C, Goodwin CR, Kosztowski TA, Bydon A, Gokaslan ZL, Wolinsky JP, Sciubba DM, Witham TF. Use of S2-alar-iliac screws associated with less complications than iliac screws in adult lumbosacropelvic fixation. Spine (Phila Pa 1976). 2017:42(3):E142-9.

6. Hasan MY, Liu G, Wong HK, Tan JH. Post-operative complications of S2AI versus iliac screw in spinopelvic fixation: a meta-analysis and recent trends review. Spine J. 2020;20(6):964-72.

7. Xu R, Ebraheim NA, Douglas K, Yeasting RA. The projection of the lateral sacral mass on the outer table of the posterior ilium. Spine (Phila Pa 1976). 1996:21(7):790-4.
8. O'Brien JR, Yu WD, Bhatnagar R, Sponseller P, Kebaish KM. An anatomic study of the S2 iliac technique for lumbopelvic screw placement. Spine (Phila Pa 1976). 2009;34(12):E439-42.

9. Kebaish KM. Sacropelvic fixation: techniques and complications. Spine (Phila Pa 1976). 2010;35(25):2245-51.

10. Bourghli A, Boissiere L, Obeid I. Dual iliac screws in spinopelvic fixation: a systematic review. Eur Spine J. 2019;28(9):2053-9.

11. Ebata S, Oba H, Ohba T, Takahashi J, Ikegami S, Koyama K, Hiroyuki Kato $\mathrm{H}$, Hirotaka HH. Surgical outcomes of long fusion using dual iliac screws bilaterally for adult spinal deformities: the effect on the loosening rate and sacroiliac joint correction. Spine Surg Relat Res. 2019;3(3):236-43.

12. Akesen B, Wu C, Mehbod AA, Sokolowski M, Transfeldt EE. Revision of loosened iliac screws. A biomechanical study of longer and bigger screws. Spine (Phila Pa 1976). 2008;33(13):1423-8.

13. König MA, Sundaram RO, Saville P, Jehan S, Boszczyk BM. Anatomical considerations for percutaneous trans ilio-sacroiliac S1 and S2 screw placement. Eur Spine J. 2016;25:1800-5.

14. Sun X, Li S, Qiu Y, Chen ZH, Chen X, Xu L, Zhu ZZ. Anatomical study of a novel iliosacral screw placement for sacrum-pelvis in adult via computed tomography reconstruction. Spine (Phila Pa 1976). 2018;43(3):E740-5.

15. O'Brien JR, Yu W, Kaufman BE, Bucklen B, Salloum K, Khalil S, Gudipally M. Biomechanical evaluation of S2 alar-iliac screws effect of length and quad-cortical purchase as compared with iliac fixation. Spine (Phila Pa 1976). 2013;38(20):E1250-1255.

16. Park YS, Hyun SJ, Park JH, Kim KJ, Jahng TA, Kim HJ. Radiographic and clinical results of free hand S2 alar-iliac screw placement for spinopelvic fixation: an analysis of 45 consecutive screws. Clin Spine Surg. 2017;30:E877-82.

17. Weisenthal BM, Doss DJ, Henry AL, Stephens BF. Optimal trajectory and length of S2 alar iliac screws: a 3-dimensional computed-aided design study. Clin Spine Surg. 2019:32(7):E335-9.

18. Sponseller PD, Zimmerman RM, Ko PS, Gunne AT, Mohamed AS, Chang $T L$, Kebaish KM. Low profile pelvic fixation with the sacral alar iliac technique in the pediatric population improves results at two-year minimum follow-up. Spine (Phila Pa 1976). 2010;35(20):1887-92.

19. Choi HY, Hyun SJ, Kim KJ, Jahng TA, Kim HJ. Freehand S2 alar-iliac screw placement using K-wire and cannulated screw: technical case series. J Korean Neurosurg Soc. 2018;61(1):75-80.

20. Phan K, Li J, Giang G, Teng I, Phan S, Chang N, Mobbs R. A novel technique for placement of sacro-alar-iliac (S2Al) screws by K-wire insertion using intraoperative navigation. J Clin Neurosci. 2017;45:324-7.

21. O'Brien JR, Matteini L, Yu WD, Kebaish KM. Feasibility of minimally invasive sacropelvic fixation: percutaneous S2 alar iliac fixation. Spine (Phila Pa 1976). 2010;35(4):460-4.

22. Tevanov I, Liciu E, Chirila MO, Dusca A, Ulici A. The use of 3D printing in improving patient-doctor relationship and malpractice prevention. Rom J Leg Med. 2017;25:279-82.

\section{Publisher's Note}

Springer Nature remains neutral with regard to jurisdictional claims in published maps and institutional affiliations.
Ready to submit your research? Choose BMC and benefit from:

- fast, convenient online submission

- thorough peer review by experienced researchers in your field

- rapid publication on acceptance

- support for research data, including large and complex data types

- gold Open Access which fosters wider collaboration and increased citations

- maximum visibility for your research: over 100M website views per year

At $B M C$, research is always in progress.

Learn more biomedcentral.com/submissions 